\title{
Perceptions of Medical Students Regarding Use of Audio-visual Aids in Lecture Delivery
}

\author{
Sushama K. Chavan ${ }^{1}$, Kalidas D. Chavan ${ }^{2}$, Purushottam A. Giri ${ }^{3}$, \\ Sandip S. Jogdand ${ }^{4}$ \\ ${ }^{1}$ Department of Anatomy, ${ }^{2}$ Department of Forensic Medicine \& Toxicology, ${ }^{3,4}$ Department of Community \\ Medicine (PSM), Rural Medical College of Pravara Institute of Medical Sciences (Deemed University), Loni, \\ Maharashtra, India
}

\begin{abstract}
Nowadays most lecture classes in various institutions conducted using advanced computer technologies, with the purpose to enhance students learning and sustain interest in the topic. Nevertheless, does that really help them? To assess the viewpoint of medical students of acceptance and preferences of methodology of teaching, in our institution the study was undertaken. The three methodologies were, lecture with chalkboard, overhead projector (OHP) with transparencies and PowerPoint (PPT) lecture on LCD. The medical students studying in different study phase were provided with questionnaire containing various attributes, pertaining to their perception for teaching methodology. Analysis of data showed chalkboard was most preferred method by the students. Students in primary phase preferred PPT lectures but students in terminal phase preferred chalkboard. The study also found gender difference to perception for $A$ - $V$ aids with male preponderance.
\end{abstract}

Keywords: A-V aids, Lecture delivery, Medical students, Perception, Teaching methodology

\section{Introduction}

"No one is taught by another, each one has to learn himself"

Medical teachers have conventionally been using different teaching methods to educate medical students that previously dominated by blackboard and slide projectors. Recently audiovisual aids such as videotapes and multimedia introduced. Critics of multimedia feel that it is expensive, time consuming, and is not worth the time and effort. [1]

Two major problems confront medical educators now, the increased intake of medical students that is now under way, and the great expansion in postgraduate medical education. The number of teachers, at present are already inadequate, will lag further behind the requirements over the next decade. To cope with these problems institutions have started exploiting advances in educational technology. We as a faculty think that it may help to improve the quality of orthodox-conventional teaching methods and which may, in the form of selfinstructional techniques, replace the teacher altogether. With AV aid, some feel that they can get away with practicing less, as they have words in front of them. At present scenario, it has thus, slowly and steadily become a method to dissipate large number of facts, interspersed with illustrations and animations, all packed in allotted time span of lecture. [2]

The audiovisual aids are the term used for devices that helps conventional teaching methods such as the lecture, clinical demonstration, or the textbook. Many aids-for example, the blackboard, charts, color transparencies with overhead projector, are already in use. However, which otherwise is teacher-centered job with more modern facilities, such as the power point presentation, audiotape, and the film loop are slowly emerging as the major source of tools in lecture delivery. As designs and expected uses of AV, aids are adding to the didactic nature of classroom teaching. Therefore, undoubtedly, these aids hold the students attention. It is said that learning style of learner, whether visual, auditory, or kinesthetic, is usually resistant to change. [1] Therefore, do they really help the student to learn? Do they sustain it throughout the duration of class? It is likely that mismatch may exist between the learning styles of students and the teaching styles of teachers. Hence, these are a few of the many questions that need to answer from students' point of view.

At present, the most common ways of lecture delivery include the lectures using PowerPoint (PPT) presentations, lectures utilizing the transparency and overhead projector (TOHP) besides the traditional 'chalk and talk' method. There is no conclusive study stating the superiority of one method over the other. However, various studies are there conducted to compare the effectiveness of lectures using PowerPoint (PPT) or other such media in comparison to the lectures using chalkboard. Garg A et al. [3] have observed that students want the teachers to include audiovisual aids during the lectures, but it is not certain whether it improves their understanding or performance in the examinations. Bartsch R et al. [4] noted that students preferred lectures 
with PPT over the use of TOHP, but in some instances the content of the PPT presentation distracted students and they performed less well in tests compared with another group given lectures using chalkboard. One extensive study comparing PowerPoint and TOHP, observed no difference in student performance in tests. [5] While in another study, there was marked improvement in examination results when PPT replaced the use of TOHP. [6] Baxi SN et al. [7] observed that an equal number of students preferred blackboard-based or multimedia-based lectures and insisted the need to be taken into consideration when using multimedia modalities to present lectures to students. Seth $\mathrm{V}$ et al. [8] noted that the majority of the medical students preferred PPT presentations, while dental students preferred chalkboard. Mohan L et al. [9] noted that the optimum use of audiovisual aid is essential for deriving their benefits.

Considering the diverse views about the use of audiovisual aids in lecturer delivery, in the present study, an attempt was made to assess the perceptions regarding use of three routinely used audiovisual aids namely chalkboard, utilizing transparencies with an overhead projector and PowerPoint presentation in lecture delivery amongst medical students.

\section{Aim and Objectives}

The aim of the study was to assess the perceptions regarding the use of audiovisual aids in lecture delivery amongst medical students.

1. To explore medical students opinion about the use of audio-visual aids in lecturer delivery

2. To compare, the opinion of students, studying in different phases about the use of A-V Aids in lecture delivery.

3. To measure, the association between the phase of students and their perceptions about the use of A-V Aids in lecture delivery.

\section{Material And Methods}

This cross sectional study conducted during May and June 2012 at Rural Medical College, Loni, an esteemed institution, located in Ahmednagar district of western Maharashtra, and imparting quality medical education since 27 years. The Medical College comprises of 571 medical students studying in different phases of MBBS. Fifty students from each phase selected by random convenient sampling thus, study sample comprised of two hundred participants. Medical students available during the study period were included in the study. Those who were not present during study period and refused to participate excluded from study.

A self-administered questionnaire designed in three parts, part A composed of demographic information of medical students. Part B contains both open and close-ended questions related to the preference and opinions for AV aids. Part C comprised of ten attributes measured, based on Likert's scale of grading as strongly agrees /Agree/ No opinion/ Disagree/ strongly disagree. The scores allotted in the aforementioned sequence are $2 / 1 / 0 /-1 /-2$. The sum of the all students grading on each attribute were taken for calculating the final weighted score. The questionnaire distributed to the study participants through a social worker, who is not involved in the research work, to maintain confidentiality and anonymity. With adoption of this distribution system students could freely express their ideas without the fear of teacher. The students were asked to fill in questionnaire about the views and perception of three AV aids in lecture delivery, viz: using a chalkboard, TOHP and PPT presentation. The filled questionnaires collected in the same manner. The data collected and verified by hand, then coded before entry to computer. Once data entry was complete, the data analyzed by mean, percentage, Chi-square test and other appropriate statistical test for non-continuous variables.

\section{Result}

Majority of the student has preferred mixed type of audio-visual aids (TABLE-1). Majority of male students perceived that chalkboard helps in grasping while majority of female students perceived mixed A-V aids for the same, this difference was not statistically significant. While both male and female students perceived chalkboard as best AV-aid that helps in thinking, the observed gender difference was not statistically significant. 
Table 1: Association between Gender and Preference of A-V aids amongst Study Participants

\begin{tabular}{|c|c|c|c|c|c|c|}
\hline \multirow[t]{2}{*}{ Gender } & \multicolumn{4}{|c|}{ A-V aids preferred } & \multirow[t]{2}{*}{ Total } & \multirow{2}{*}{$\begin{array}{c}\text { Test of } \\
\text { significance }\end{array}$} \\
\hline & Chalkboard & $\mathrm{OHP}$ & PPT & Mixed & & \\
\hline Male & $29(34.22 \%)$ & $1(1.18 \%)$ & $18(21.18 \%)$ & $37(43.53 \%)$ & 85 & \multirow{3}{*}{$\begin{array}{l}\text { Monte-carlo } \\
\text { significance } \\
\mathrm{p}=0.390\end{array}$} \\
\hline Female & $28(24.35 \%)$ & $4(3.48 \%)$ & $29(25.22 \%)$ & $54(46.96 \%)$ & 115 & \\
\hline \multirow[t]{3}{*}{ Total } & 57 & 5 & 47 & 91 & 200 & \\
\hline & \multicolumn{4}{|c|}{ A-V aids helps grasping } & \multirow[t]{2}{*}{ Total } & \\
\hline & Chalkboard & $\mathrm{OHP}$ & PPT & Mixed & & \\
\hline Male & $33(38.82 \%)$ & $4(4.71 \%)$ & $16(18.82 \%)$ & $32(37.65 \%)$ & 85 & Fischer's exact test \\
\hline Female & $38(33.04 \%)$ & $3(2.61 \%)$ & $25(21.74 \%)$ & $49(42.61 \%)$ & 115 & $=1.633$ \\
\hline \multirow[t]{3}{*}{ Total } & 71 & 7 & 41 & 81 & 200 & $\mathrm{P}=.720$ \\
\hline & \multicolumn{4}{|c|}{ A-V aids help thinking } & \multirow[t]{2}{*}{ Total } & \\
\hline & Chalkboard & OHP & PPT & Mixed & & \\
\hline Male & $47(55.29 \%)$ & $3(3.53 \%)$ & $13(15.29 \%)$ & $22(25.88 \%)$ & 85 & \multirow{3}{*}{$\begin{array}{l}\text { Monte- carlo } \\
\text { significance } \\
\mathrm{p}=0.360\end{array}$} \\
\hline Female & $50(43.48 \%)$ & $1(0.87 \%)$ & $23(20 \%)$ & $41(35.65 \%)$ & 115 & \\
\hline Total & 97 & 4 & 36 & 63 & 200 & \\
\hline
\end{tabular}

Majority of the students from first and second study phase (TABLE-II) preferred mixed A-V aids, while students from third and fourth phase preferred chalkboard; this was statistically significant observed difference. The students from first, third and fourth study phase, perceived as chalkboard helps in thinking as compared to other AV-aids. Students of first phase perceived PPT as helps in thinking process. While second phase students perceived as mixed A-V aids helps in thinking which was statistically significant. Majority of study participants from first and second study phase perceive mixed A-V aids as helpful tool for grasping while students from third and fourth study phase perceive chalkboard as helpful A-V aids in grasping. This observed difference was also significant statistically.

Table II: Association between study phase and preference of A-aid amongst study participants

\begin{tabular}{|c|c|c|c|c|c|c|}
\hline \multirow[t]{2}{*}{ Study phase } & \multicolumn{4}{|c|}{$\mathrm{A}-\mathrm{V}$ aids preferred } & \multirow[t]{2}{*}{ Total } & \multirow{2}{*}{$\begin{array}{c}\text { Test of } \\
\text { significance }\end{array}$} \\
\hline & Chalk-Board & $\mathrm{OHP}$ & PPT & Mixed & & \\
\hline I MBBS & $6(12 \%)$ & $4(8 \%)$ & $20(40 \%)$ & $20(40 \%)$ & 50 & \multirow{5}{*}{$\begin{array}{c}\text { Monte-carlo } \\
\mathrm{p}=.001\end{array}$} \\
\hline II MBBS & $6(12 \%)$ & $1(2 \%)$ & $8(16 \%)$ & $35(70 \%)$ & 50 & \\
\hline III MBBS Part-I & $19(38 \%)$ & $0(0 \%)$ & $14(28 \%)$ & $17(34 \%)$ & 50 & \\
\hline III MBBS Part-II & $26(52 \%)$ & $0(0 \%)$ & $5(10 \%)$ & $19(38 \%)$ & 50 & \\
\hline \multirow[t]{3}{*}{ Total } & 57 & 05 & 47 & 91 & 200 & \\
\hline & \multicolumn{4}{|c|}{ A-V aids helps thinking } & \multirow[t]{2}{*}{ Total } & \\
\hline & Chalk-Board & $\mathrm{OHP}$ & PPT & Mixed & & \\
\hline I MBBS & $18(36 \%)$ & $1(2 \%)$ & $19(38 \%)$ & $12(24 \%)$ & 50 & \multirow{5}{*}{$\begin{array}{c}\text { Monte-carlo } \\
\mathrm{P}=0.02\end{array}$} \\
\hline II MBBS & $20(40 \%)$ & $0(0 \%)$ & $7(14 \%)$ & $23(46 \%)$ & 50 & \\
\hline III MBBS Part-I & $28(56 \%)$ & $2(4 \%)$ & $7(14 \%)$ & $13(26 \%)$ & 50 & \\
\hline III MBBS Part-II & $31(62 \%)$ & $1(2 \%)$ & $3(6 \%)$ & $15(30 \%)$ & 50 & \\
\hline \multirow[t]{3}{*}{ Total } & 97 & 4 & 36 & 63 & 200 & \\
\hline & \multicolumn{4}{|c|}{ A-V aids help grasping } & \multirow[t]{2}{*}{ Total } & \\
\hline & Chalk-Board & OHP & PPT & Mixed & & \\
\hline I MBBS & $7(14 \%)$ & $3(6 \%)$ & $18(36 \%)$ & $22(44 \%)$ & 50 & \multirow{5}{*}{$\begin{array}{l}\text { Monte- carlo } \\
\mathrm{P}=0.0001\end{array}$} \\
\hline II MBBS & $14(28 \%)$ & $1(2 \%)$ & $10(20 \%)$ & $25(50 \%)$ & 50 & \\
\hline III MBBS Part-I & $22(44 \%)$ & $3(6 \%)$ & $11(22 \%)$ & $14(28 \%)$ & 50 & \\
\hline III MBSS Part-II & $28(56 \%)$ & $0(0 \%)$ & $2(4 \%)$ & $20(40 \%)$ & 50 & \\
\hline Total & 71 & 7 & 41 & 81 & 200 & \\
\hline
\end{tabular}

Association between attributes and preference of AV-aids, depicted in (TABLE- III). To analyze the best method of audio visual aid in use for independent attributes, ranking scale was adopted allotting the sequence in ascending order. It is evident that mean ranking for OHP and PPT were lower than that of chalkboard. On application of "Friedman test" a significant association was found $(p<0.001)$, which conclude that the chalkboard was the most preferred A-V aids by participants for the attributes.

Table III: Association between attributes and preference of AV-aids

\begin{tabular}{|c|c|c|c|c|c|c|c|c|c|c|}
\hline \multirow[t]{2}{*}{ Attributes } & \multicolumn{3}{|c|}{ Chalk-board } & \multicolumn{3}{|c|}{ OHP } & \multicolumn{3}{|c|}{ PPT } & \multirow{2}{*}{$\begin{array}{l}\text { Stat. sig. } \\
\text { (Friedman } \\
\text { test) }\end{array}$} \\
\hline & Mean & S.D. & $\begin{array}{l}\text { Media } \\
\mathrm{n}\end{array}$ & Mean & S.D. & $\begin{array}{l}\text { Media } \\
\mathrm{n}\end{array}$ & Mean & S.D. & Median & \\
\hline $\begin{array}{l}\text { Organization of } \\
\text { lecture good }\end{array}$ & 4.1550 & 0.845 & 4.00 & 3.145 & 1.077 & 3.00 & 3.905 & 0.985 & 4.00 & $\mathrm{P}<0.001$ \\
\hline $\begin{array}{l}\text { Contents are well } \\
\text { informative }\end{array}$ & 3.705 & 0.966 & 4.00 & 3.425 & 1.049 & 4.00 & 4.075 & 0.997 & 4.00 & $\mathrm{P}<0.001$ \\
\hline $\begin{array}{l}\text { Highlights } \\
\text { important points }\end{array}$ & 3.905 & 0.949 & 4.00 & 3.565 & 1.040 & 4.00 & 4.215 & 0.879 & 4.00 & $\mathrm{P}<0.001$ \\
\hline Maintains & 4.110 & 0.939 & 4.00 & 3.175 & 1.058 & 3.00 & 3.535 & 1.129 & 4.00 & $\mathrm{P}<0.001$ \\
\hline
\end{tabular}


Perceptions of Medical Students Regarding Use of Audio-visual Aids in Lecture Delivery

\begin{tabular}{|l|l|l|l|l|l|l|l|l|l|l|}
\hline $\begin{array}{l}\text { continuity of } \\
\text { thought }\end{array}$ & & & & & & & & & & \\
\hline $\begin{array}{l}\text { Clear and } \\
\text { understandable }\end{array}$ & 4.065 & 0.930 & 4.00 & 3.325 & 1.065 & 4.00 & 3.825 & 0.948 & 4.00 & $\mathrm{P}<0.001$ \\
\hline $\begin{array}{l}\text { Better } \\
\text { explanation }\end{array}$ & 4.360 & 0.827 & 5.00 & 3.170 & 1.066 & 3.00 & 3.695 & 1.003 & 4.00 & $\mathrm{P}<0.001$ \\
\hline $\begin{array}{l}\text { Better } \\
\text { summarization }\end{array}$ & 3.620 & 1.049 & 4.00 & 3.405 & 1.117 & 4.00 & 4.045 & 0.989 & 4.00 & $\mathrm{P}<0.001$ \\
\hline $\begin{array}{l}\text { Notes } \\
\text { taking/copying } \\
\text { diagrams easier }\end{array}$ & 4.175 & 0.979 & 4.00 & 3.250 & 1.142 & 3.00 & 3.590 & 1.178 & 4.00 & $\mathrm{P}<0.001$ \\
\hline $\begin{array}{l}\text { Stimulate the } \\
\text { interest }\end{array}$ & 4.080 & 1.044 & 4.00 & 3.130 & 1.081 & 3.00 & 3.780 & 1.080 & 4.00 & $\mathrm{P}<0.001$ \\
\hline $\begin{array}{l}\text { Lecture delivery } \\
\text { interesting }\end{array}$ & 4.080 & 0.999 & 4.00 & 3.085 & 1.124 & 3.00 & 3.750 & 1.083 & 4.00 & $\mathrm{P}<0.001$ \\
\hline
\end{tabular}

Mean ranking of study group according to their audio-visual preferences was shown in (TABLE- IV). Chalkboard was found best $\mathrm{A}-\mathrm{V}$ aids for overall attributes with higher mean ranking of 22.95 and mean ranking for PPT was 17.95 and mean ranking of 5.6 for $\mathrm{OHP},(\mathrm{H}=8.66 ; \mathrm{df}=2 \mathrm{p}<0.05)$ This difference was statistically significant.

Table IV: Mean ranking of study group according to their audio-visual preferences

\begin{tabular}{|l|l|c|c|c|}
\hline $\begin{array}{l}\text { Sr. } \\
\text { n. }\end{array}$ & \multicolumn{1}{|c|}{ Attributes } & $\begin{array}{c}\text { Chalk-board total score } \\
\text { (mean rank) }\end{array}$ & $\begin{array}{c}\text { OHP total score } \\
\text { (mean rank) }\end{array}$ & $\begin{array}{c}\text { PPT total score } \\
\text { (mean rank) }\end{array}$ \\
\hline 1. & Organization of lecture is good & $831(27)$ & $629(3)$ & $781(19.5)$ \\
\hline 2. & Contents are well informative & $741(15)$ & $685(9)$ & $815(23)$ \\
\hline 3. & Highlights important points & $781(19.5)$ & $713(11)$ & $843(29)$ \\
\hline 4. & Maintain continuity of thought & $822(26)$ & $635(5)$ & $707(10)$ \\
\hline 5. & Clear and understandable & $813(22)$ & $665(7)$ & $765(18)$ \\
\hline 6. & Better explanation & $872(30)$ & $634(4)$ & $739(14)$ \\
\hline 7. & Better summarization & $724(13)$ & $681(8)$ & $809(21)$ \\
\hline 8. & Note taking/copying diagrams & $835(28)$ & $650(6)$ & $718(12)$ \\
\hline 9. & Stimulate the interest & $816(24.5)$ & $626(2)$ & $756(17)$ \\
\hline 10. & Lecture delivery interesting & $816(24.5)$ & $617(1)$ & $750(16)$ \\
\hline & Total score & 229.5 & 56 & 179.5 \\
\hline & Mean rank & 22.95 & 5.6 & 17.95 \\
\hline
\end{tabular}

\section{Discussion}

The present study revealed that majority of the students feels AV-aids are essential for lecture delivery and suggested change of AV-aids according to topic. Majority of students preferred mixed A-V aids followed by traditional chalkboard. Similarly, a study done by Giri PA et al. [10] found that use of a combination of audiovisual aids was more appreciated by the undergraduate medical students. Another study done by Kumar A et al. [11] also found that $50.0 \%$ students showed a preference for the use of a combination of audio-visual aids during the lecture delivery. A study by Mohan L et al. [9] also found consistent results with our study-reporting majority of students in their study group preferred mixed A-V aids especially for understanding a particular topic. There was no gender difference found amongst study participants regarding perceptions of A-V aids use. While a study done by, Seth V et al. [8] at Jaipur revealed that majority of medical students $(65.33 \%)$ have preferred PPT amongst their study participants. Another study done by Lalvarmawi F et al. [12] also revealed that postgraduate students preferred the use of PPT presentation as the mode of lecture delivery to the other modes.

Our study participants revealed that with the chalkboard lectures can be well organized, can maintain continuity of thought, better-explained lectures are more clear and understandable, stimulates interest and helps students for taking notes /copy diagram. The main reasons for preferring chalkboard were that the lectures contained natural pauses and breaks, allowing students to follow the material. While students perceived that lecture were informative, better summarized, and highlights important points with the use of PPT. Studies done by Seth V et al. [8] and Lalvarmawi F et al. [12] found similar results, which supports our study. However, they found their study participants reported that lectures are well organized with PPT and were clearly audible and informative with TOHP, which was not consistent with our study results.

Over-all our study revealed blackboard as the most preferred A-V aid by the study participants. Mohan L et al. [9] opined that in blackboard based teaching students are active participants and better able to cope with the teaching speed of the teacher. It motivates an interest in learning and helps in holding attention in the class. 
This may be the reason for preferring chalkboard as A-V aid in our study. In addition, study participants feel that teachers uncomfortable with use of $\mathrm{A}-\mathrm{V}$ aids might drive students more in favor of chalkboard.

Third and fourth phase students prefers chalkboard as better teaching aids. Teachers should take note of the reasons why a significant number of students still prefer 'outdated 'teaching modalities compared with computer-based presentations. The choice of multimedia by first phase medical students is also not surprising, as multimedia material shown to explain complicated topics with the aid of pictures, graphs, animations, and simulations.

\section{Conclusion}

The present study revealed that chalkboard was the most preferred method by the students. There was significant gender difference found for the preference of A-V aids with male preponderance. In addition, study phase of students found associated with preference to A-V aids. Students in primary phase show preference to PPT and mixed A-V aids while the students in further phases prefer chalkboard as method of choice. This may be because of changing learning attitudes of students with change in the learning phase of students. In addition, there may be need of training of teachers pertaining to use of these A-V aids and newer technologies.

\section{Acknowledgement}

We express our deep sense of gratitude to the Management, Pravara Medical Trust and Dr. Devidas S. Kulkarni, Principal, Rural Medical College Loni. We also acknowledge the help and support of Dr. Shashank D. Dalvi, Vice-chancellor, Pravara Institute of Medical Sciences (Deemed University), Loni, Maharashtra, India.

\section{References}

[1]. Murray-Harvey R. Learning styles and approaches to learning: distinguishing between concepts and instruments. Br J Educ Psychol 1994; 64: 373-388.

[2]. Thomas M, Appala RB. Are PowerPoint presentations fulfilling its purpose? South East Asian Journal of Medical Education 1990; $1: 38-41$.

[3]. Garg A, Rataboli PV, Muchandi K. Students' opinion on the prevailing teaching methods in pharmacology and changes recommended. Indian J Pharmacol 2004; 36:155-8.

[4]. Bartsch RA, Cobern K. Effectiveness of PowerPoint presentations in lectures. Comput Educ 2003; 41:77-86.

[5]. Szabo A, Hastings N. Using IT in the undergraduate classroom: should we replace the blackboard with PowerPoint? Comput Educ $2000 ; 35: 175-87$.

[6]. Lowry RB. Electronic presentation of lectures - effect upon student performance. U Chem Educ 1999; 8:18-21.

[7]. Baxi SN, Shah CJ, Parmar RD, Parmar D, Tripathi CB. Students' perception of different teaching aids in a medical college. AJHPE 2009; 1(1):15-16.

[8]. Seth V, Upadhyaya P, Ahmad M, Moghe V. PowerPoint or chalk and talk: Perceptions of medical students versus dental students in a medical college in India. Adv Med Educ Pract, 2010;1:11-6.

[9]. Mohan L, Shankar PR, Kamath A, Manish MS, Eesha BR. Students' Attitudes towards the Use of Audio Visual Aids during Didactic Lectures In Pharmacology. Journal of Clinical and Diagnostic Research 2010; 4:3363-3368.

[10]. Giri PA, Phalke DB. Views regarding use of audio-visual aids during didactic lectures in community medicine among first year medical students of Rural Medical College, Loni, Maharashtra. Nat J Res Comm Med 2013; 2(2):145-48.

[11]. Kumar A, Singh R, Mohan L, Kumar MK. Student's views on audio visual aids used during didactic lectures in a medical college. Asian J Med Sci 2013;4:36-40.

[12]. Lalvarmawi F, Ningthoujam S, U, N, Mishra M. Perception of postgraduate students on teaching aids. J Med Soc 2013;27:36-8. 